ive to ventilation, and by impairment of diffusion of oxygen to the central rapid stream through grossly dilated microvessels. The relative importance of these three mechanisms appears to vary widely between patients, and the studies reported here do not allow us to distinguish between them in this case.

During the period of study treatment with prednisolone (20 mg every other day) and azathioprine (150 mg daily) was unchanged. We cannot correlate the improvement with beta-blockade since there was no response to the initial two weeks of treatment and subsequent improvement was maintained and enhanced over a period of six months with no propranolol (fig 2). It is possible that a period of beta-blockade might permanently switch off or diminish the secretion of some undefined vasodilator, but this is so speculative that we prefer the hypothesis that the improvement was unrelated to treatment. If so, one must treat with caution reports of improvement following drug treatment in individual patients. ${ }^{6}$ The improvement in lung function was not matched by any correlated change in liver function. No biopsy was performed during the study period.

Although a fall in $\mathrm{SaO}_{2}$ during exercise would be predicted in patients with low resistance pathways through the lungs, we know of no other systematic study of this point in patients with the hepatopulmonary syndrome. In particular, although it is well known that in the hepatopulmonary syndrome administration of pure oxygen will raise $\mathrm{SaO}_{2}$ to $100 \%$ at rest, we think this is the first demonstration of the same effect in moderate exercise. Serial exercise studies with non-invasive measurement of $\mathrm{SaO}_{2}$ proved to be an effective method of assessing this patient, and we recommend them providing they are supervised by appropriate staff and terminated if necessary at previously determined tolerance levels.

The authors thank Dr J D Maxwell for referring the patient for assessment.

1 Berthelot P, Walker JG, Sherlock S, Reid L. Arterial changes in the lungs in cirrhosis of the liver - lung spider naevi. N Engl f Med 1966;274:291-8.

2 Davis HH, Schwartz DJ, Lefrak SS, Susanan N, Schainker $B A$. Alveolar-capillary oxygen disequilibrium in hepatic cirrhosis. Chest 1978;73:507-11.

3 Rodriguez-Roisin R, Agusti AGN, Roca J. The hepatopulmonary syndrome: new name, old complexities. Thorax 1992;47:897-902.

4 Chilvers ER, Peters AM, George P, Hughes JMB, Allison DJ. Quantification of right to left shunt through pulmonary arteriovenous malformations using ${ }^{99} \mathrm{Tc}^{\mathrm{m}}$ albumin microspheres. Clin Radiol 1988;39:611-4.

5 Hayes PC, Davis JM, Lewis JA, Bouchier IAD. Metaanalysis of value of propranolol in prevention of variceal haemorrhage. Lancet 1990;336:153-6.

6 Cadranel JL, Milleron BJ, Cadranel J-F, Fermand J-P, Andrivet $\mathrm{P}$, Brouet J-C, et al. Severe hypoxemia-associated intrapulmonary shunt in a patient with chronic liver disease: improvement after medical treatment. $A m$ Rev Respir Dis 1992;146:526-7.

\section{Late asthmatic response to inhaled glacial acetic acid}

\author{
S Kivity, E Fireman, Y Lerman
}

\begin{abstract}
A patient with bronchial asthma who developed a late asthmatic response to inhalation challenge with glacial acetic acid is presented. This is believed to be the first description of a reaction to this allergen in an asthmatic patient.
\end{abstract}

(Thorax 1994;49:727-728)

Exposure to glacial acetic acid has so far been reported to induce either reactive airway disease, as described following accidental exposure, ${ }^{1}$ or interstitial pneumonitis. ${ }^{2}$ We report a patient with suspected asthma to glacial acetic acid who developed a late reaction to inhalation challenge with glacial acetic acid carried out in a special environmental chamber.

\section{Case report}

The patient was a 58 year old man who had developed asthma over the previous two years. He reported having asthma during childhood, but had been symptom-free from the age of 11 to 56 years. Over the previous two years, however, he had been exposed to glacial acetic acid in the canning factory where he worked. Glacial acetic acid was used in the pickling of cucumbers and the fumes were released into the surrounding air. Exposure to glacial acetic acid fumes occurred during the 10 minute process of heating the mixture when the patient stood in the vicinity unmasked. A few months after the initial exposure he began having asthmatic attacks which were relieved with salbutamol. Symptoms occurred initially only on working days, but soon became more frequent, occurring also over weekends and on holidays. As the symptoms worsened he was given daily treatment with high dose beclamethasone dipropionate $(800 \mu \mathrm{g} /$ day $)$, supplemented with salbutamol as required.

Exposure to a small amount of glacial acetic acid was on a daily basis, and occasionally to increased amounts, with subsequent worsening of symptoms. Shortness of breath occurred a few hours after exposure to glacial acetic acid and continued also at home. Occasional exposure to cigarette smoke, cold air, or other irri-

Received 15 February 1993 28 May 1993 
tants did not exacerbate symptoms. He denied smoking or exposure to other known airway irritants or sensitisers. Skin testing to multiple environmental allergens (prick test, allergens from Hollister Stier) did not show immediate skin sensitivity. Baseline pulmonary function tests included determination of spirometric parameters (Fukuda Spiroanalyzer) and lung volume using a body plethysmograph (Jaeger Master Lab) with the following results, expressed as a percentage of the predicted values: slow vital capacity (VC) $=78 \%$; thoracic gas volume $(\mathrm{TGV})=172 \%$; total lung capacity $(\mathrm{TLC})=130 \%$; forced expiratory volume in one second $\left(\mathrm{FEV}_{1}\right)=56 \% ; \mathrm{FEV}_{1} /$ $\mathrm{VC} \%=54 \%$. Inhalation of salbutamol resulted in the following improvements, presented as a percentage from the initial baseline values: $\mathrm{TGV}=36 \%, \mathrm{FVC}=27 \%$, $\mathrm{FEV}_{1}=30 \%$. Inhalation challenge to glacial acetic acid was performed in an environmental unit with clean air, obtained by using Heppa and charcoal filters and kept below $\mathrm{cm} \mathrm{H}_{2} \mathrm{O}$ positive pressure to prevent exposure to other outdoor irritants. Three different inhalation challenges were used with the Morgan dosimeter using the method of Chai et al. ${ }^{3}$ The airway response to methacholine showed a $\mathrm{PC}_{20}$ of $0.01 \mathrm{mg}$, consistent with active bronchial asthma. On two separate days the patient was exposed to a small amount of glacial acetic acid for 10 minutes, after which spirometric parameters were measured every half hour. In both instances there was a decrease in $\mathrm{FEV}_{1}$ (expressed as percentage fall from baseline value) with less than a $5 \%$ fall in VC: exposure 1, 30\% decrease at two hours; exposure $2,34 \%$ decrease at 2.5 hours. Salbutamol inhalation successfully reversed the fall. Pulmonary function tests performed for four hours on another day did not show any significant change, as seen following glacial acetic acid $\left(<10 \%\right.$ change in $\left.\mathrm{FEV}_{1}\right)$.

\section{Discussion}

Glacial acetic acid has been reported to be associated with reversible airway obstruction following exposure to large amounts. ${ }^{1}$ Inhalation challenge was not performed in any of these patients. We report the first asthmatic patient where inhalation challenge with glacial acetic acid induced a late asthmatic response. The patient denied asthmatic symptoms following non-specific irritants such as smoke, cold air, or others. One can therefore assume that glacial acetic acid does not induce asthma, and that our patient had preexisting asymptomatic airway hyperreactivity since he had suffered from childhood asthma. Exposure to glacial acetic acid may have induced a late airway response leading to chronic inflammation and severe bronchial asthma. As a result of the late response glacial acetic acid can be considered as a sensitiser and not an irritant.

Late asthmatic response to inhaled allergen is considered to be the main mechanism for the development of bronchial asthma, both in atopic patients and in occupational exposure. ${ }^{4}$ Our patient could not recall exposure to large amounts of glacial acetic acid, such as is seen with a spill. It seems, therefore, that he was not suffering from a reactive airway syndrome but rather from occupational asthma. Our report will add to the accumulating knowledge on occupational triggers of airway disease.

Kern DG Outbreak of reactive airways dysfunction syndrome after a spill of glacial acetic acid. Am Rev Respir Dis drome after a spill of

2 Rajan KG, Davies BH. Reversible airways obstruction and interstitial pneumonitis due to acetic acid. $\mathrm{Br} \mathcal{F}$ Ind $\mathrm{Med}$ 1989;46:67-8.

3 Chai H, Farr RS, Froehlich LA, Mathison DA, McLean JA Rosenthal RR, et al. Standardization of bronchial inhalation challenge procedures. $\mathcal{f}$ Allergy Clin Immunol 1975;56:323-7.

4 O'Byrne PM, Dolovich J, Hargreave FE. Late asthmatic responses. Am Rev Respir Dis 1987;134:740-51. 